\title{
The development and the psychometric evaluation of the Adolescents Intentions towards the Birth Options Scale in Greek
}

\author{
Dimitra Varnakioti ${ }^{1}$, Kleanthi Gourounti ${ }^{1}$, Antigoni Sarantaki ${ }^{1}$, Chara Tzavara ${ }^{2}$, Aikaterini Lykeridou ${ }^{1}$
}

\begin{abstract}
INTRODUCTION Worldwide, the rising of caesarean section rates is a major public health issue. Little is known regarding birth attitudes held by students who are the next generation of parents. The aim of this study was to develop and assess the psychometric properties of the Adolescents Intentions towards Birth Options Scale (AIBOS), a self-report and short instrument assessing intentions towards birth options in young adolescents.

METHODS The AIBOS was framed by Ajzen's theory of planned behavior and developed in a three-phase process using an integrated mixed-methods approach that included literature reviews, professional focus groups, and a psychometric survey evaluation. The psychometric evaluation was conducted by recruiting a sample of 480 high school students. Content validity, exploratory factor analysis, discriminant and construct validity, test-retest reliability and internal consistency were explored.

RESULTS The expert panel determined that the content validity was satisfactory. The final 17 -item scale consisted of five factors explaining $48.9 \%$ of the total variance in the data. Discriminant validity was satisfactory. Cronbach's a coefficient was over 0.7 for each factor, indicating acceptable internal consistency of the questionnaire. There was significant agreement in all subscales as emerged from test-retest.

conclusions The AIBOS demonstrated good content validity, an easily interpretable five-factor structure, acceptable internal consistency, high test-retest reliability, and satisfactory discriminant and construct validity with sample characteristics. It is an easily comprehensible, easily completed tool, which matches the culture of young adolescents.
\end{abstract}

\section{AFFILIATION \\ 1 Department of Midwifery, \\ School of Health and Care \\ Sciences, University of West Attica, Athens, Greece \\ 2 Centre for Health Services \\ Research, Department of \\ Hygiene, Epidemiology and \\ Medical Statistics, Medical \\ School, National and \\ Kapodistrian University of \\ Athens, Athens, Greece \\ CORRESPONDENGE TO \\ Dimitra Varnakioti. Department of Midwifery, School of Health and Care Sciences, University of West Attica, Agiou Spiridonos 28, Egaleo, GR-12243, Athens, Greece. E-mail: dvarnakioti@ uniwa.gr ORCID ID: https://orcid. org/0000-0002-6171-3878}

\section{KEYWORDS \\ adolescents, birth options, planned behavior theory \\ Received: 15 December 2021 \\ Revised: 17 December 2021 \\ Accepted: 19 January 2022}

\section{INTRODUCTION}

It has been more than thirty-five years since 1985 when the international healthcare community considered that the ideal rate for caesarean sections has to be between $10 \%$ and $15 \%{ }^{1}$. In accordance with this, recent studies indicate that CS rates higher than $10 \%$ are not associated with reductions in maternal and newborn mortality rates ${ }^{2}$. A caesarean section is a lifesaving procedure; however, it is associated with both maternal and perinatal risks while there is no evidence showing any benefits of the procedure for women or infants where it is not required ${ }^{3}$. However, in the last decades there has been an unprecedented and steady rise in CS rates in both developed and developing countries ${ }^{4}$. This could be explained through a complex multivariate analysis model; changes both regarding the distinguishing characteristics of the mother (increased percentage of elderly nulliparous women) and professional practice styles, personalized medicine instead of team obstetrical care, increased legal pressure for malpractice (defensive treatment), along with economic, organizational, social, and cultural factors ${ }^{5-7}$.

In Greece, the national rate has been climbing the last 
years, reaching $56.8 \%$ in 2016 or more in some areas ${ }^{8}$. A recent study indicates that in Greece, most women continue to give birth by CS, which leads to a major public health problem with economic, ethical and humanitarian implications ${ }^{9}$. In 2019, experts from the Organization of United Nations noted that in Greece the law about maternity protection was not being implemented uniformly and expressed concern about ongoing discrimination based on pregnancy and family responsibilities ${ }^{10}$. Many strategies have been introduced to reduce CS rates, including the continuing education of clinicians and communities regarding the benefits of vaginal birth and the risks of unnecessary CSs. While the investigation for interventional approaches is ongoing, worries have focused on the psychosocial and behavioral factors that affect and are affected by the dominance of caesarean delivery ${ }^{11,12}$.

Social cognitive theory models indicating that attitudes directly affect behaviors are currently being tested to predict preferred birth approaches ${ }^{13-17}$. Ajzen's theory of planned behavior (TPB) has been successfully used to explain and predict behavior in a multitude of behavioral domains, from physical activity to drug use, from recycling to the choice of travel mode, from safer sex to consumer behavior, and from technology adoption to protection of privacy. According to this theory, human behavior is guided by three considerations: attitude toward the behavior, social pressure or subjective norm, and perceived behavioral control. A behavioral belief is the person's subjective probability that performing a behavior of interest will lead to a particular outcome or provide a specific experience. Subjective norms refer to the expectation that others important to the person (e.g. friends, family, spouse, co-workers, one's physician or supervisor) approve or disapprove the behavior under consideration or essential others themselves perform the behavior. Perceived behavior control refers to people's beliefs that they can perform a given behavior. As a general rule, the more favorable the attitude and the subjective norm, and the greater the perceived control, the stronger should be the person's intention to perform the behavior in question, which in our study is the choice of vaginal birth. Intention is thus assumed to be the immediate antecedent of behavior ${ }^{17}$.

Little is known regarding birth attitudes held by students who are the next generation of parents. Previous studies suggest that apart from the rise in the caesarean section rate, university students think about childbirth as a painful but normal process and report knowledge gaps regarding birth decisions ${ }^{18-20}$. Additional studies confirm that most young adults are misinformed regarding the common necessity of most childbirth interventions and the risks associated with performing those interventions when they are not medically necessary ${ }^{21-25}$. However, according to the author's knowledge, there are no published studies on the birth attitudes of younger people, such as students of secondary education. Similarly, the authors were unable to identify any published studies regarding the development and use of tools measuring the birth attitudes of students. Therefore, this study aimed to develop and assess the psychometric properties of a self-report and short instrument assessing intentions towards birth options in young adolescents.

\section{METHODS \\ Study design}

This study was designed for scale development. The scale was prepared in the Greek language, and its development included three main phases: item generation, item reduction, initial validity testing (content validity testing), construct validity testing (exploratory factor analysis [EFA], reliability testing and criterion-related validity).

\section{Instrument development}

Phase I: Item generation

The goal of phase I was to generate the items for the instrument from two main sources: a) an extensive literature review identifying data that examined attitudes towards birth decisions among men and women (pregnant and nonpregnant); and b) a focus group including six experts from different fields to evaluate the content validity index (CVI) of the developed questionnaire, a midwife, two university professors in midwifery, a PhD candidate from the University of West Attica, a high school educator and a clinical psychologist with a cognitive-behavioral background. Finally, a 19-item pool of items regarding attitudes and intentions on birth options in young populations was established. It is worth mentioning that the Childbirth Fear to Prior pregnancy scale (CFPP), assessing fear of childbirth prior to pregnancy, has been a significant guide to developing our instrument ${ }^{26}$.

\section{Phase II: Content validity testing}

Once the item pool was developed from phase I, the goals of phase II were to assess the content validity and reduce the number of questions for further scale development by assembling the panel of experts. The 19 items that were kept were the clearest and the most concise.

The content validity was assessed by determining the face validity and the content validity index $(\mathrm{CVI})$. To evaluate whether items were relevant, clear, and essential, experts were given a critical appraisal sheet with the following four inquiries: 1) the relevance of each question in the tool (how important the question is); 2) the clarity of each question (how clear the wording is); 3) the essentiality of each question (how necessary the question is); and 4) recommendations for improvement of each question (reference). The experts were asked to rate each item on a 4-point scale ranging from 1 to 4 ( 1 = not relevant, 2 = somewhat relevant, 3 = quite relevant, and $4=$ highly relevant) according to the applicability of the expression and content to the local culture and the research objective. Ratings of 1 and 2 are considered content invalid, while ratings of 3 and 4 are considered content valid. The CVI of each item (I-CVI) was calculated as the ratio of the number of 'quite relevant' and 'highly relevant' expert opinion responses to the number of experts. The overall $\mathrm{CVI}$ of the questionnaire was calculated as the average of the I-CVIs of all items. Items with an I-CVI lower than 0.78 
were considered candidates for revision, and items with very low values were candidates for deletion. A CVI rating greater than 0.8 represented satisfactory content validity ${ }^{27,28}$. The experts suggested revision in two questions to match with the culture and the background of young adolescents. The majority of items were considered relevant, with an I-CVI over 0.78 .

Phase III: Reliability and validity testing

The goals of the phase III were to assess validity, explore the instrument's factor structure and internal consistency by using Cronbach's alpha coefficient, the tool's stability, by evaluating the test-retest reliability via intraclass correlation coefficient (ICC), and the discriminant and construct validity.

\section{Sample}

The study was conducted in fourteen vocational high schools in Greece. Data were collected between October 2019 and April 2021. All students of first grade were invited to participate. A total sample of 480 students consented to participate. Due to the specialty of the project, instructions were provided by the researchers in every school unit, and additional clarifications were available for each of the students during the questionnaire administration.

The test-retest reliability of the questionnaire was calculated for 30 students of the sample who agreed to repeat AIBOS two weeks after the first administration.

\section{Instruments}

The version of the AIBOS that emerged from phases I, II, and III, of the instrument development process consisted of 19 items designed to access the constructs of the theory of planned behavior. The questionnaire is a multidimensional instrument assessing the three main dimensions of the theory of planned behavior (attitudes, subjective norms and perceived behavioral control) by five factors: 'Cognitive attitude towards vaginal birth', 'Cognitive attitude towards caesarean section', 'Affective attitude', 'Subjective norms', and 'Perceived behavioral control'. The 'Cognitive attitude towards vaginal birth' factor was measured by six items, 'Cognitive attitude towards caesarean section' factor was measured by four items and the 'Affective attitude' factor was measured by three items. 'Subjective norms' factor was measured by 2 items and 'perceived behavioral control' factor was measured by 2 questions. Every question was answered by a 5 -item Likert scale ranging from 'strongly disagree $=1$ ' to 'strongly agree $=5$ '. Lower scores indicated negative attitudes and higher scores indicated positive attitudes.

Sociodemographic characteristics, sources of information regarding giving birth and educational needs were also examined. Permission for the use of the entire AIBOS can be obtained from the corresponding author at the request of professionals or organizations who wish to use it.

\section{Data analysis}

Quantitative variables were expressed as means with standard deviation (SD), and absolute and relative frequencies. Exploratory factor analysis was carried out to evaluate construct validity, disclose underlying structures and reduce the number of items. Principal component analysis (PCA) was chosen as an extraction method using varimax rotation. Kaiser-Meyer-Olkin procedure for measuring sample adequacy was applied. The cut-off point for factor loadings was 0.40 and for eigenvalues was 1.00. Internal consistency reliability was determined by the calculation of Cronbach's a coefficient. Factors with a coefficient $\geq 0.70$ were considered acceptable. Intraclass correlation coefficient (ICC) was used to assess the reliability of the questionnaire, from test-retest procedure. Discriminant construct validity was evaluated by analyzing the association between the factors of the questionnaire and gender, field of study, and preference for a specific type of labor using Student's t-tests. Statistical significance was set at $p<0.05$ and analyses were conducted using SPSS statistical software (version 24.0).

\section{RESULTS}

\section{Sample characteristics}

The sample consisted of 480 teenagers, aged 14-17 years with a mean age of 15.5 years (SD: 0.6). Sample's characteristics are presented in Table 1. More than half $(54.2 \%)$ of the teenagers were girls. Almost all teenagers (97.7\%) were born in Greece. Most of the teenagers had parents who had completed high school. Moreover, 55.8\% of the teenagers had chosen to study health sciences. Also, $89.0 \%$ of the teenagers would like to have children and $78.5 \%$ would prefer a vaginal labor for them or their partner.

Teenagers' knowledge and attitude towards vaginal labor are presented in Table 2. Most participants strongly agreed with the statements 'I believe that people significant for me (family, relatives) would prefer my delivery (my partner's delivery) to be vaginal' and 'I believe that healthcare providers (obstetricians, midwives) would prefer my delivery (my partner's delivery) to be vaginal', $61.3 \%$ and $52.9 \%$, respectively. Only, $2.3 \%$ of the sample strongly agreed with the statement "I see vaginal birth as an outdated method of childbirth' and $2.5 \%$ with the statement 'Caesarean section is safer for the mother'.

\section{Table 1. Sample characteristics, Greece $(\mathrm{N}=480)$}

\begin{tabular}{|lr|}
\hline Characteristics & $\boldsymbol{n}(\%)$ \\
\hline Age, mean (SD) & $15.5(0.6)$ \\
\hline Gender & \\
\hline Boys & $209(43.5)$ \\
\hline Girls & $260(54.2)$ \\
\hline Prefer not to say & $11(2.3)$ \\
\hline Born in Greece & $469(97.7)$ \\
\hline Father's highest level of education & $69(14.4)$ \\
\hline Primary school & $268(55.8)$ \\
\hline High school & $78(16.3)$ \\
\hline Technical School/Vocational Training Institute (VTI)
\end{tabular}

Continued 
Table 1. Continued

\begin{tabular}{|lr}
\hline Characteristics & $\boldsymbol{n}(\%)$ \\
\hline University degree & $53(11)$ \\
\hline Post-graduate degree & $8(1.7)$ \\
\hline PhD & $4(0.8)$ \\
\hline Mother's highest level of education & \\
\hline Primary school & $44(9.2)$ \\
\hline High school & $251(52.3)$ \\
\hline Technical School/Vocational Training Institute (VTI) & $92(19.2)$ \\
\hline University degree & $74(15.4)$ \\
\hline Post-graduate degree & $14(2.9)$ \\
\hline PhD & $5(1.0)$ \\
\hline Field of study & \\
\hline Agriculture and Environment & $8(1.7)$ \\
\hline Administration and Economics & $42(8.8)$ \\
\hline Structured Environment and Architectural Design & $9(1.9)$ \\
\hline Applied Arts & $15(3.2)$ \\
\hline Electronics and Automation & $19(4.0)$ \\
\hline Engineering & $55(11.6)$ \\
\hline Shipping and Maritime Studies & $16(3.4)$ \\
\hline Computing studies & $46(9.7)$ \\
\hline Health sciences & $265(55.8)$ \\
\hline Can you imagine yourself having children & \\
\hline somewhere in the future? & $427(89.0)$ \\
\hline Nes & $53(11.0)$ \\
\hline Assuming & \\
\hline
\end{tabular}

Assuming you could choose the type of birth for your baby, what would you prefer it to be?

Vaginal birth

377 (78.5)

Caesarean section delivery

$103(21.5)$

\section{Factor structure of the AlBOS}

The results from the exploratory factor analysis are presented in Table 3. KMO value was 0.7 and Bartlett's test of sphericity was statistically significant, $(x 2=, d f=$, $p<0.001$ ). The proposed five factors were finally confirmed by the emerging factor analysis. All factors combined explained $48.9 \%$ of the variance. Factor 'Cognitive attitude towards vaginal labor' had 6 items and explained $13.1 \%$ of the variance. Factor "Cognitive attitude towards caesarean section' had 4 items and explained $10.6 \%$ of the variance. Factor 'Affective attitude' had 3 items and explained 9.1\% of the variance. Factors 'Subjective norms' and 'Perceived behavior control' had 2 items each and explained $8.4 \%$ and $7.7 \%$ of the variance, respectively. Two items ('In Greece, most women give birth with vaginal delivery' and 'In Greece, most women give birth with caesarean section delivery') initially attributed to the cognitive attitude factors had loadings lower than 0.4, thus were deleted and were not included in these factors. Therefore, the instrument finally consisted of 17 items. Cronbach's a coefficient was $>0.7$ for each factor, indicating acceptable internal consistency of the questionnaire. The overall Cronbach a coefficient was 0.76 .

\section{Test-retest reliability}

Test-retest results are presented in Table 4. There was significant agreement in all factors as emerged from testretest.

\section{Discriminant construct validity}

To access the discriminant validity of the questionnaire, demographic variables (gender) and students' future preferences (field of studies, mode of delivery) were associated with instrument factors. It was found that girls had significantly greater mean scores in all factors, except of 'Knowledge on caesarean section', compared to

Table 2. Participants' answers, in each statement separately $(N=480)$

\begin{tabular}{|c|c|c|c|c|c|}
\hline & $\begin{array}{c}\text { Strongly } \\
\text { disagree } \\
\text { n (\%) }\end{array}$ & $\begin{array}{c}\text { Disagree } \\
\text { n (\%) }\end{array}$ & $\begin{array}{c}\text { Neither } \\
\text { agree nor } \\
\text { disagree } \\
n(\%)\end{array}$ & $\begin{array}{l}\text { Agree } \\
n(\%)\end{array}$ & $\begin{array}{c}\text { Strongly } \\
\text { agree } \\
n(\%)\end{array}$ \\
\hline $\begin{array}{l}\text { Normal or vaginal birth is a completely natural process that } \\
\text { occurs at the end of a pregnancy and the baby is delivered } \\
\text { vaginally }\end{array}$ & $6(1.3)$ & $15(3.1)$ & $87(18.1)$ & $241(50.2)$ & $131(27.3)$ \\
\hline $\begin{array}{l}\text { Women give birth mainly by normal childbirth and } \\
\text { caesarean sections in a population should not be more } \\
\text { than a small percentage of all births }\end{array}$ & $18(3.8)$ & $57(11.9)$ & $191(39.8)$ & $168(35.0)$ & $46(9.6)$ \\
\hline In Greece most women give birth with vaginal delivery & $26(5.4)$ & $87(18.1)$ & $176(36.7)$ & $158(32.9)$ & $33(6.9)$ \\
\hline Vaginal birth is safer for the mother & $11(2.3)$ & 57 (11.9) & $119(24.8)$ & $178(37.1)$ & $115(24)$ \\
\hline Vaginal birth is safer for the baby & $11(2.3)$ & $48(10.0)$ & $165(34.4)$ & $170(35.4)$ & $86(17.9)$ \\
\hline After a vaginal birth the recovery time is faster and the & $16(3.3)$ & $44(9.2)$ & $164(34.2)$ & $170(35.4)$ & $86(17.9)$ \\
\hline
\end{tabular}


Table 2. Continued

\begin{tabular}{|c|c|c|c|c|c|}
\hline & $\begin{array}{c}\text { Strongly } \\
\text { disagree } \\
\text { n (\%) }\end{array}$ & $\begin{array}{c}\text { Disagree } \\
\text { n (\%) }\end{array}$ & $\begin{array}{c}\text { Neither } \\
\text { agree nor } \\
\text { disagree } \\
n(\%)\end{array}$ & $\begin{array}{l}\text { Agree } \\
\text { n (\%) }\end{array}$ & $\begin{array}{c}\text { Strongly } \\
\text { agree } \\
\text { n (\%) }\end{array}$ \\
\hline $\begin{array}{l}\text { Normal childbirth activates the early bonding of mother- } \\
\text { newborn and increases the success of breastfeeding }\end{array}$ & $9(1.9)$ & $35(7.3)$ & $207(43.1)$ & $164(34.2)$ & $65(13.5)$ \\
\hline $\begin{array}{l}\text { A caesarean section delivery is a surgical procedure } \\
\text { required only for medically indicated reasons (the safety of } \\
\text { the mother or the baby) }\end{array}$ & $23(4.8)$ & $84(17.5)$ & $91(19.0)$ & $170(35.4)$ & $112(23.3)$ \\
\hline $\begin{array}{l}\text { Caesarean section could be seen as a means to avoid the } \\
\text { pain of a vaginal birth }\end{array}$ & $34(7.1)$ & 95 (19.8) & $149(31)$ & $160(33.3)$ & $42(8.8)$ \\
\hline Caesarean section is safer for the mother & $57(11.9)$ & $124(25.8)$ & $215(44.8)$ & $72(15)$ & $12(2.5)$ \\
\hline Caesarean section is safer for the baby & $45(9.4)$ & $95(19.8)$ & $233(48.6)$ & $92(19.2)$ & $14(2.9)$ \\
\hline $\begin{array}{l}\text { Caesarean section could be suggested to provide the } \\
\text { convenience to schedule the time of childbirth }\end{array}$ & $23(4.8)$ & $43(9.0)$ & $233(48.5)$ & $141(29.4)$ & $40(8.3)$ \\
\hline $\begin{array}{l}\text { In Greece most women give birth with caesarean section } \\
\text { delivery }\end{array}$ & $15(3.1)$ & $125(26.0)$ & $196(40.8)$ & $111(23.1)$ & $33(6.9)$ \\
\hline Vaginal birth is generally unpredictable & $11(2.3)$ & $44(9.2)$ & $122(25.4)$ & $216(45)$ & $87(18.1)$ \\
\hline I see vaginal birth as an outdated method of childbirth & $123(25.6)$ & $160(33.3)$ & $123(25.6)$ & $63(13.1)$ & $11(2.3)$ \\
\hline $\begin{array}{l}\text { I believe that people significant for me (family, relatives) } \\
\text { would prefer my delivery (my partner's delivery) to be } \\
\text { vaginal }\end{array}$ & $53(11.0)$ & $28(5.8)$ & $8(1.7)$ & $97(20.2)$ & $294(61.3)$ \\
\hline $\begin{array}{l}\text { I believe that healthcare providers (obstetricians, midwives) } \\
\text { would prefer my delivery (my partner's delivery) to be } \\
\text { vaginal }\end{array}$ & $86(17.9)$ & $23(4.8)$ & $11(2.3)$ & $106(22.1)$ & $254(52.9)$ \\
\hline $\begin{array}{l}\text { I think that I (my partner) will have self-control and will } \\
\text { confidently handle the process and the pain of a childbirth }\end{array}$ & $34(7.1)$ & $67(14.0)$ & $161(33.5)$ & $151(31.5)$ & $67(14)$ \\
\hline $\begin{array}{l}\text { I think that labor pain will be too intense. I am afraid that I } \\
\text { (my partner) might panic and not know what to do during } \\
\text { labor and birth }\end{array}$ & $32(6.7)$ & $113(23.5)$ & $156(32.5)$ & $121(25.2)$ & $58(12.1)$ \\
\hline
\end{tabular}

Table 3. Loadings from exploratory factor analysis with principal components method, after varimax rotation $(\mathrm{N}=480)$

\begin{tabular}{|c|c|c|c|c|c|c|}
\hline & & $\begin{array}{l}\text { Knowledge } \\
\text { on vaginal } \\
\text { labor }\end{array}$ & $\begin{array}{c}\text { Knowledge } \\
\text { on } \\
\text { caesarean } \\
\text { section }\end{array}$ & $\begin{array}{l}\text { Affective } \\
\text { attitude }\end{array}$ & $\begin{array}{l}\text { Subjective } \\
\text { norms }\end{array}$ & $\begin{array}{l}\text { Perceived } \\
\text { behavior } \\
\text { control }\end{array}$ \\
\hline 1 & $\begin{array}{l}\text { Normal or vaginal birth is a completely natural } \\
\text { process that occurs at the end of a pregnancy and } \\
\text { the baby is delivered vaginally }\end{array}$ & & & 0.59 & & \\
\hline 2 & $\begin{array}{l}\text { Women give birth mainly by normal childbirth and } \\
\text { caesarean sections in a population should not be } \\
\text { more than a small percentage of all births }\end{array}$ & 0.64 & & & & \\
\hline 3 & In Greece most women give birth with vaginal delivery & & & & & \\
\hline 4 & Vaginal birth is safer for the mother & 0.72 & & & & \\
\hline 5 & Vaginal birth is safer for the baby & 0.71 & & & & \\
\hline 6 & $\begin{array}{l}\text { After a vaginal birth the recovery time is faster and } \\
\text { the postpartum painless }\end{array}$ & 0.44 & & & & \\
\hline 7 & $\begin{array}{l}\text { Normal childbirth activates the early bonding of } \\
\text { mother-newborn and increases the success of } \\
\text { breastfeeding }\end{array}$ & 0.40 & & & & \\
\hline
\end{tabular}


Table 3. Continued

\begin{tabular}{|c|c|c|c|c|c|c|}
\hline & & $\begin{array}{l}\text { Knowledge } \\
\text { on vaginal } \\
\text { labor }\end{array}$ & $\begin{array}{l}\text { Knowledge } \\
\text { on } \\
\text { caesarean } \\
\text { section }\end{array}$ & $\begin{array}{l}\text { Affective } \\
\text { attitude }\end{array}$ & $\begin{array}{l}\text { Subjective } \\
\text { norms }\end{array}$ & $\begin{array}{c}\text { Perceived } \\
\text { behavior } \\
\text { control }\end{array}$ \\
\hline 8 & $\begin{array}{l}\text { A caesarean section delivery is a surgical procedure } \\
\text { required only for medically indicated reasons (the } \\
\text { safety of the mother or the baby) }\end{array}$ & 0.45 & & & & \\
\hline 9 & $\begin{array}{l}\text { Caesarean section could be seen as a means to avoid } \\
\text { the pain of a vaginal birth }\end{array}$ & & 0.53 & & & \\
\hline 10 & Caesarean section is safer for the mother & & 0.72 & & & \\
\hline 11 & Caesarean section is safer for the baby & & 0.71 & & & \\
\hline 12 & $\begin{array}{l}\text { Caesarean section could be suggested to provide the } \\
\text { convenience to schedule the time of childbirth }\end{array}$ & & 0.40 & & & \\
\hline 13 & $\begin{array}{l}\text { In Greece most women give birth with caesarean } \\
\text { section delivery }\end{array}$ & & & & & \\
\hline 14 & Vaginal birth is generally unpredictable & & & 0.60 & & \\
\hline 15 & $\begin{array}{l}\text { I see vaginal birth as an outdated method of } \\
\text { childbirth }\end{array}$ & & & -0.48 & & \\
\hline 16 & $\begin{array}{l}\text { I believe that people significant for me (family, } \\
\text { relatives) would prefer my delivery (my partner's } \\
\text { delivery) to be vaginal }\end{array}$ & & & & 0.42 & \\
\hline 17 & $\begin{array}{l}\text { I believe that healthcare providers (obstetricians, } \\
\text { midwives) would prefer my delivery (my partner's } \\
\text { delivery) to be vaginal }\end{array}$ & & & & 0.41 & \\
\hline 18 & $\begin{array}{l}\text { I think that I (my partner) will have self-control and } \\
\text { will confidently handle the process and the pain of a } \\
\text { childbirth }\end{array}$ & & & & & -0.81 \\
\hline 19 & $\begin{array}{l}\text { I think that labor pain will be too intense. I am afraid } \\
\text { that I (my partner) might panic and not know what to } \\
\text { do during labor and birth }\end{array}$ & & & & & 0.84 \\
\hline \multicolumn{2}{|c|}{$\%$ Variance explained } & 13.1 & 10.6 & 9.1 & 8.4 & 7.7 \\
\hline \multicolumn{2}{|c|}{ Cronbach's a } & 0.75 & 0.75 & 0.71 & 0.78 & 0.77 \\
\hline \multicolumn{2}{|c|}{ Mean (SD) } & $3.53(0.61)$ & $3.00(0.64)$ & $3.78(0.63)$ & $4.01(1.13)$ & $2.91(0.92)$ \\
\hline
\end{tabular}

Table 4. Intraclass correlation coefficients (ICC) from test-retest

\begin{tabular}{|c|c|c|}
\hline & $I C C$ & $p$ \\
\hline Knowledge on vaginal labor & 0.85 & $<0.001$ \\
\hline Knowledge on caesarean section & 0.82 & $<0.001$ \\
\hline Affective attitude & 0.90 & $<0.001$ \\
\hline Significant others & 0.89 & $<0.001$ \\
\hline Perceived behavior control & 0.87 & $<0.001$ \\
\hline
\end{tabular}

boys. Teenagers who would study health sciences in the future had significantly greater scores in 'Knowledge on vaginal labor', 'Affective attitude', 'Significant others' and significantly lower scores in 'Knowledge on caesarean section' comparison to teenagers who would study nonmedical sciences. Moreover, teenagers who would prefer to have a vaginal birth for themselves or their partner had significantly greater scores in 'Knowledge on vaginal labor', 'Affective attitude', 'Significant others', 'Perceived behavior control' and significantly lower scores in 'Knowledge on caesarean section' in comparison to teenagers who would prefer to have a caesarean section. Associations between participants' gender, field of study and selected type of labor are given in the Supplementary file.

\section{DIscussion}

Birth-related attitudes and beliefs have been constantly examined during pregnancy, however availability of data regarding adolescents' attitudes towards birth options are rather scarce.

Studies propose strategies that involve eliminating prejudice towards vaginal childbirth through raising awareness regarding the side effects of CS and the benefits of vaginal birth. Moreover, strategies that promote women's confidence towards their ability to deliver naturally would potentially reduce unnecessary CS rates ${ }^{29-33}$. However, high rates of CS could suggest that these interventions may not 
be either consistently or timely implemented.

Recent research suggests for the immediate commencement of interventions aimed at reducing CS rates before parenthood, as birth stances are formed prior to pregnancy and are potentially influenced by modifiable factors such as fear of childbirth and lack of knowledge regarding birth decisions ${ }^{34-36}$.

The purpose of this study was to develop and validate a self-report measure of intentions towards birth options among young adolescents via the various components of the TPB. Consequently, the questionnaire was developed to examine adolescent's attitudes towards vaginal birth and caesarean section (knowledge, beliefs, feelings), adolescent's perceptions of significant others' beliefs about birth options, adolescent's perceived behavior control and intentions regarding birth options. Therefore, the questionnaire was named Adolescent's Intentions towards Birth Options Scale (AIBOS)

Through an iterative, rigorous instrument development process, the AIBO scale was developed and tested. The AIBOS was developed by using an integrated mixed methods approach that included literature reviews, professional focus groups, expert consultations, and a psychometric survey evaluation. The AIBO scale demonstrated good content validity, an easily interpretable five-factor structure, acceptable internal consistency and test-retest reliability, and satisfactory discriminant validity with sample characteristics.

The results of the exploratory factor analysis suggest that discriminative capacity existed among the items and that a five-factor solution was the most appropriate. The factors were interpreted and labelled: 'cognitive component of vaginal birth', 'cognitive component of caesarean section', 'affective component of vaginal birth', 'subjective normssignificant others' and 'perceived behavior control', in accordance with the TPB.

The five-factor solution of the AIBO 17 -item scale cumulatively accounted for $48.9 \%$ of the variance. Convergent validity (e.g. the extent to which a test correlates with other variables with which it theoretically should correlate) could not be assessed because, and according to our knowledge, no other validated instrument measuring attitudes to birth options in adolescents was available.

Known groups method testing showed that girls had significantly greater scores in all factors, except for 'Knowledge on caesarean section', compared to boys. Teenagers who would study health sciences had significantly greater scores in 'Knowledge on vaginal labor', 'Affective attitude', 'Significant others' and significantly lower scores in 'Knowledge on caesarean section'. Moreover, teenagers who would prefer a vaginal labor for them or their partner had significantly greater scores in 'Knowledge on vaginal labor', 'Affective attitude', 'Significant others', 'Perceived behavior control', and significantly lower scores in 'Knowledge on caesarean section'.

\section{Limitations}

Results of this study need to be interpreted within the light of some limitations. First, convenience sampling was used, although that was not planned. The research protocol had anticipated the participation of schools from various geographically located departments; however, the emergence of COVID-19 pandemic made all school communities rather skeptical of all live activities. Additionally, the sample of students was drawn only from vocational high schools due to the limitations of the Institute of Educational Policy (I.E.P) that suggests any surveys need to be integrated in relative courses. It is worth mentioning that ideally the researchers would have liked to collect data about the emotional state of the participants, but was prevented by a number of limitations due to the low average age of the sample. Thus, the results of this study may have introduced a selection bias and produced a non-representative sample of students, therefor they are not likely to be generalizable. It is essential to explore the psychometric properties and assess this scale among students from different settings (e.g. general high schools) and different geographical regions.

\section{CONGLUSIONS}

The AIBOS was found to have satisfactory psychometric properties with a meaningful five-factor structure, good internal reliability and good discriminant and construct validity. It is an easily comprehensible, easily completed scale, which matches with the culture and the lifestyle of young adolescents. Since a wide range of non-clinical interventions are intended to reduce unnecessary caesarean section births, targeting evaluation towards various stakeholders (women or families, healthcare professionals, healthcare organizations or facilities), AIBOS may be used for evaluating intentions towards birth options long before parenthood starts. Future research should investigate the factorial structure of the AIBOS and must be verified in another sample of students through a confirmatory factor analysis.

\section{REFERENGES}

1. Appropriate technology for birth. Lancet. 1985;326(8452):436437. doi:10.1016/SO140-6736(85)92750-3

2. Ye J, Zhang J, Mikolajczyk R, Torloni MR, Gülmezoglu AM, Betran AP. Association between rates of caesarean section and maternal and neonatal mortality in the 21 st century: a worldwide population-based ecological study with longitudinal data. BJOG. 2016;123(5):745-753. doi:10.1111/1471-0528.13592

3. Sandall J, Tribe RM, Avery L, et al. Short-term and longterm effects of caesarean section on the health of women and children. Lancet. 2018;392(10155):13491357. doi:10.1016/S0140-6736(18)31930-5

4. Brüggmann D, Löhlein LK, Louwen F, et al. Caesarean Section--A Density-Equalizing Mapping Study to Depict Its Global Research Architecture. Int J Environ Res Public Health. 2015;12(11):14690-14708. doi:10.3390/ijerph121114690

5. Linton A, Peterson MR, Williams TV. Effects of maternal characteristics on cesarean delivery rates among U.S. Department of Defense healthcare 
beneficiaries, 1996-2002. Birth. 2004;31(1):3-11. doi:10.1111/j.0730-7659.2004.0268.x

6. Mossialos E, Allin S, Karras K, Davaki K. An investigation of Caesarean sections in three Greek hospitals: the impact of financial incentives and convenience. Eur J Public Health. 2005;15(3):288-295. doi:10.1093/eurpub/ckiOO2

7. Yang YT, Mello MM, Subramanian SV, Studdert DM. Relationship between malpractice litigation pressure and rates of cesarean section and vaginal birth after cesarean section. Med Care. 2009;47(2):234-242. doi:10.1097/MLR.Ob013e31818475de

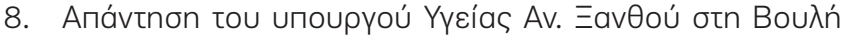

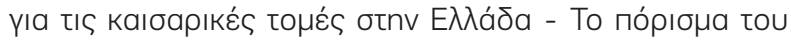
ПOY. Answer of the Health Minister An. Ksanthou in the Greek Parliament regarding ceasarean sections in Greece - The WHO Report. Report in Greek. Greek Health Ministry; 2017. March 14, 2017. Accessed December 17, 2021. https://www.moh.gov.gr/articles/ministry/ grafeio-typoy/press-releases/4509-apanthsh-toyypoyrgoy-ygeias-an-ksanthoy-sth-boylh-to-porismatoy-poy-gia-tis-kaisarikes-tomes-sthn-ellada

9. Antoniou E, Orovou E, Iliadou M, et al. Factors Associated with the Type of Cesarean Section in Greece and Their Correlation with International Guidelines. Acta Inform Med. 2021;29(1):38-44. doi:10.5455/aim.2021.29.38-44

10. End of mission statement by the UN Working Group on the issue of discrimination against women in law and in practice to its visit to Greece. ohchr.org. April 12, 2019. Accessed December 17, 2021. https:// www.ohchr.org/en/NewsEvents/Pages/DisplayNews. aspx? NewsID $=24471 \&$ LangID $=\mathrm{E}$

11. Stoll KH, Hauck YL, Downe S, Payne D, Hall WA. Preference for cesarean section in young nulligravid women in eight OECD countries and implications for reproductive health education. Reprod Health. 2017;14(1):116. doi:10.1186/s12978-017-0354-x

12. Schantz C, de Loenzien M, Goyet S, Ravit M, Dancoisne A, Dumont A. How is women's demand for caesarean section measured? A systematic literature review. PLoS One. 2019;14(3):e0213352. doi:10.1371/journal.pone.0213352

13. Rosenstock IM. The Health Belief Model and Preventive Health Behavior. Health Educ Monogr. 1974;2(4):354386. doi:10.1177/109019817400200405

14. Fishbein M, Ajzen I. Belief, attitude, intention and behavior: An introduction to theory and research. Addison-Wesley;1975

15. Ajzen I.The theory of planned behavior. Organ Behav Hum Decis Process. 1991;50(2):179-211. doi:10.1016/0749-5978(91)90020-T

16. Albert Bandura A. Health promotion from the perspective of social cognitive theory. Psychol Health. 1998;13(4):623649. doi:10.1080/08870449808407422

17. Ajzen I. The theory of planned behavior: Frequently asked questions. Hum Behav Emerg Technol. 2020;2(4):314324. doi:10.1002/hbe2.195

18. Lampman C, Phelps A. College students' knowledge and attitudes about cesarean birth. Birth. 1997;24(3):159164. doi:10.1111/j.1523-536x.1997.tb00580.x

19. Cleeton ER. Attitudes and beliefs about childbirth among college students: results of an educational intervention. Birth. 2001;28(3):192-200. doi:10.1046/j.1523-536x.2001.00192.x

20. DeJoy SB. "Midwives are nice, but ...": perceptions of midwifery and childbirth in an undergraduate class. J Midwifery Womens Health. 2010;55(2):117-123. doi:10.1016/j.jmwh.2009.05.009

21. Stoll K, Fairbrother N, Carty E, et al. "It's all the rage these days": University students' attitudes toward vaginal and cesarean birth. Birth. 2009;36(2):133-140. doi:10.1111/j.1523-536X.2009.00310.x

22. Stoll K, Hall W, Janssen P, Carty E. Why are young Canadians afraid of birth? A survey study of childbirth fear and birth preferences among Canadian University students. Midwifery. 2014;30(2):220-226. doi:10.1016/j.midw.2013.07.017

23. Handan O, Gulay R. University Students' Attitudes toward Natural Birth. Journal of Gynecology and Womens Health. 2017;7(4):555717. doi:10.19080/JGWH.2017.07.555717

24. Žigić Antić L, Nakić Radoš S, Jokić-Begić N. Are nonpregnant women afraid of childbirth? Prevalence and predictors of fear of childbirth in students. $J$ Psychosom Obstet Gynaecol. 2019;40(3):226-231. doi:10.1080/0167482X.2018.1470162

25. Mete A, Alparslan O. Investigating University Students' Preferences for Mode of Delivery. Int J Caring Sci. 2018;11(3):1408-1415. Accessed December 17, 2021. http://www.internationaljournalofcaringsciences. org/docs/8._mete_originall_11_3.pdf

26. Stoll K, Hauck Y, Downe S, et al. Cross-cultural development and psychometric evaluation of a measure to assess fear of childbirth prior to pregnancy. Sex Reprod Healthc. 2016;8:49-54. doi:10.1016/j.srhc.2016.02.004

27. Polit DF, Beck CT, Owen SV. Is the CVI an acceptable indicator of content validity? Appraisal and recommendations. Res Nurs Health. 2007;30(4):459467. doi:10.1002/nur.20199

28. Gignac GE. Psychometrics and the Measurement of Emotional Intelligence. In: Parker JDA, Saklofske DH, Stough C, eds. Assessing Emotional Intelligence: Theory, Research, and Applications. Springer;2009:9-40. doi:10.1007/978-0-387-88370-0_2

29. Fenwick J, Toohill J, Gamble J, et al. Effects of a midwife psycho-education intervention to reduce childbirth fear on women's birth outcomes and postpartum psychological wellbeing. BMC Pregnancy Childbirth. 2015;15:284. doi:10.1186/s12884-015-0721-y

30. Bagherian-Afrakoti N, Alipour A, Pourasghar M, Ahmad Shirvani M. Assessment of the efficacy of group counselling using cognitive approach on knowledge, attitude, and decision making of pregnant women about modes of delivery. Health Care Women Int. 2018;39(6):684-696. do i:10.1080/07399332.2018.1428804 
31. Yousefzadeh S, Esmaeili Darmiyan M, Asadi Younesi MR, Shakeri M. The Effect of a Training Program during Pregnancy on the Attitude and Intention of Nulliparous Women to Choose the Delivery Mode. Journal of Midwifery and Reproductive Health. 2016;4(3):704711. doi:10.22038/jmrh.2016.7162

32. Hajizadeh S, Tehrani FR, Simbar M, Farzadfar F. Effects of Recruiting Midwives into a Family Physician Program on Women's Awareness and Preference for Mode of Delivery and Caesarean Section Rates in Rural Areas of Kurdistan. PLoS One. 2016;11(4):e0151268. doi:10.1371/journal.pone.0151268

33. Preis H, Gozlan M, Dan U, Benyamini Y. A quantitative investigation into women's basic beliefs about birth and planned birth choices. Midwifery. 2018;63:46-51. doi:10.1016/j.midw.2018.05.002

34. Haines H, Rubertsson C, Pallant JF, Hildingsson I. Womens' attitudes and beliefs of childbirth and association with birth preference: a comparison of a Swedish and an Australian sample in mid-pregnancy. Midwifery. 2012;28(6):e850-e856. doi:10.1016/j.midw.2011.09.011

35. Salomonsson B, Gullberg MT, Alehagen S, Wijma K. Self-efficacy beliefs and fear of childbirth in nulliparous women. J Psychosom Obstet Gynaecol. 2013;34(3):116121. doi:10.3109/0167482X.2013.824418

36. Hall WA, Stoll K, Hutton EK, Brown H. A prospective study of effects of psychological factors and sleep on obstetric interventions, mode of birth, and neonatal outcomes among low-risk British Columbian women. BMC Pregnancy Childbirth. 2012;12:78. doi:10.1186/1471-2393-12-78

\section{ACKNOWLEDGMENTS}

The authors would like to thank Kathrin Stoll of the Birth Place Lab, Canada, for her permission to use the CFFP scale, for the development of the AIBO scale of our survey. The author's deep gratitude also goes to the study subjects who volunteered and gave their time to provide all the relevant information for the study.

\section{CONFLICT OF INTERESTS}

The authors have completed and submitted the ICMJE Form for Disclosure of Potential Conflicts of Interest and none was reported.

\section{FUNDING}

There was no source of funding for this research.

ETHIGAL APPROVAL AND INFORMED CONSENT

The study protocol was reviewed and approved by the Institute of Educational Policy (I.E.P) which is the scientific agency that provides support to the Minister of Education and Religious Affairs on issues regarding secondary education (No $\$ 12 / 124243 / \Delta 4$; $1 / 8 / 2019$ ). Written informed consent was obtained from all the participants and their parents before filling in the questionnaires.

\section{DATA AVAILABILITY}

The data supporting this research are available from the authors on reasonable request.

\section{AUTHORS' CONTRIBUTIONS}

DV initiated the research, wrote the research proposal, conducted the field work, supervised data entry, analyzed the data and wrote the manuscript. KG designed the research process, supervised data analysis, interpreted the data and co-wrote the manuscript. CT analyzed the data. AS participated in interpretation of data and $\mathrm{KL}$ supervised the study. All the authors read and approved the final manuscript.

\section{PROVENANGE ANd PEER REVIEW}

Not commissioned; externally peer reviewed. 